\title{
Major Peroxisomal Membrane Polypeptides Are Synthesized in Cultured Skin Fibroblasts from Patients with Zellweger Syndrome
}

\author{
YASUYUKI SUZUKI, NOBUYUKI SHIMOZAWA, TADAO ORII, AND TAKASHI HASHIMOTO \\ Department of Pediatrics, Gifu University School of Medicine, Gifu 500, Japan [Y.S., N.S., T.O.]; Department of \\ Biochemistry, Shinshu University School of Medicine, Matsumoto 390, Japan [T.H.]
}

\begin{abstract}
Biosynthesis of three major peroxisomal membrane polypeptides $(70,26$, and $22 \mathrm{kD})$ were investigated in an attempt to account for the absence of peroxisomes in patients with Zellweger syndrome. Immunoblot analysis using membrane fractions of autopsied livers revealed that 70 - and $22-\mathrm{kD}$ polypeptides were deficient in three Japanese patients with this syndrome. However, pulse-labeling and chase experiments using cultured skin fibroblasts demonstrated that $70-, 26$, and $22-\mathrm{kD}$ polypeptides were synthesized in these patients at levels similar to those in the controls. No significant difference in the degradation rates of these polypeptides was noted between the patients and the controls. Subcellular fractionation after pulse-chase experiments revealed $70-\mathrm{kD}$ polypeptides present in a membrane fraction of the cells. These observations indicate that at least 70-, 26-, and 22-kD peroxisomal membrane polypeptides are normally synthesized and considered to be transported into the disorganized peroxisomal membrane in patients with Zellweger syndrome. Molecular and functional analyses of these polypeptides are underway to clarify whether they contribute to membrane integrity or to the transport of peroxisomal matrix enzymes. (Pediatr Res 26: 150-153, 1989)
\end{abstract}

\section{Abbreviations}

IMP, integral membrane polypeptide MEM, minimal essential medium

The cerebro-hepato-renal syndrome of Zellweger (McKusick 21410 ) is a fatal autosomal recessive disease, with clinical findings including severe neurologic abnormalities, dysmorphic features, hepatomegaly and multiple renal cysts (1). This disorder is characterized by the absence of peroxisomes (2) and regarded as a prototype of peroxisomal disorders such as neonatal adrenoleukodystrophy, infantile Refsum's disease, rhizomelic chondrodysplasia punctata, hyperpipecolic acidemia (3), and Zellwegerlike syndrome (4). Although a number of metabolic defects, including $\beta$-oxidation system (4-6), plasmalogen biosynthesis (7, 8), phytanic acid oxidation (9), and pipecolic acid oxidation (10) have been linked to Zellweger syndrome, the primary etiology of

Received January 31, 1989; accepted April 15, 1989.

Correspondence Yasuyuki Suzuki, M.D., Department of Pediatrics, Gifu University School of Medicine, Tsukasa-machi 40, Gifu 500, Japan.

Supported in part by Grants-in-Aid for Scientific Research (61304046, 63870041 ) from the Ministry of Education, Science and Culture of Japan, and by a Research Grant for study of Intractable Diseases from the Ministry of Health and Welfare of Japan, and by Grant (62-6) from the National Center of Neurology and Psychiatry of the Ministry of Health and Welfare of Japan. this syndrome is still unknown. Multiple deficiencies of peroxisomal enzymes are considered to be caused by failure of localization into peroxisomes and by a secondary degradation once they are synthesized, presumably caused by a defect in biogenesis of the normal peroxisomes.

There are at least two hypotheses regarding the biogenesis of peroxisomes. The classical model of budding theory, in which peroxisomes are formed by budding from the endoplasmic reticulum (11), has been challenged by a new model in which new peroxisomes are formed from preexisting ones (12). The latter theory is supported by findings that both matrix enzymes (13) and IMP of peroxisomes $(14,15)$ are synthesized on free polysomes and are subsequently localized in the organelle. IMP are considered to have important roles for the integrity of the membrane, localization of matrix enzymes, and transport of metabolites.

Recently, an abnormality of an IMP of peroxisomes was postulated for the primary etiology of Zellweger syndrome and neonatal adrenoleukodystrophy (16). Lazarow et al. (17) reported that $22-\mathrm{kD}$ IMP of peroxisomes and peroxisomal membrane ghosts (18) are present in patients with Zellweger syndrome. We previously reported that 70-kD IMP was synthesized in a patient with this syndrome (19). In this report, we investigated the biosynthesis and intracellular localization of three major IMP $(70,26$, and $22 \mathrm{kD})$ in three Japanese patients with Zellweger syndrome to evaluate more precisely the roles of these IMP for the etiology of this syndrome.

\section{MATERIALS AND METHODS}

Three control patients with conditions not associated with known peroxisomal diseases and three patients with Zellweger syndrome were investigated. All Zellweger patients were Japanese and typical findings including accumulation of very long-chain fatty acids, absent peroxisomal enzymes and undetectable peroxisomes were found. They died within several months after birth and autopsied organs were stored at $-80^{\circ} \mathrm{C}$ until use.

Immunoblotting. Membrane fractions of liver tissues were obtained according to the method of Fujiki et al. (20) with slight modifications. The liver $(0.5 \mathrm{~g})$ was homogenized with $5 \mathrm{~mL}$ of $0.1 \mathrm{M}$ potassium phosphate buffer, $\mathrm{pH} 8$, and centrifuged for 45 min at $40000 \mathrm{rpm}(140000 \times g)($ Hitachi model 70P-72, Hitachi Koki, Katsuta, Japan). The precipitate was homogenized with 5 $\mathrm{mL}$ of $0.1 \mathrm{M} \mathrm{Na}_{2} \mathrm{CO}_{3}$, cooled on ice for $30 \mathrm{~min}$ and recentrifuged for $45 \mathrm{~min}$ at $40000 \mathrm{rpm}$. The membrane fraction was solubilized with $0.5 \mathrm{~mL}$ of $2 \%$ SDS, sonicated, and treated with an equal volume of sample buffer $(125 \mathrm{mM}$ Tris- $\mathrm{HCl}, \mathrm{pH}$ 6.8/5\% SDS/ $0.32 \mathrm{M} \beta$-mercaptoethanol/20\% glycerol $/ 0.005 \%$ Bromophenol blue). A total of $20 \mu \mathrm{L}$ of this sample was applied to SDS/10\% PAGE (21). Western blotting was performed as described (22). A nitrocellulose sheet was blocked with $3 \%$ BSA, and the membrane polypeptides were located on the sheet using anti-70-, 26-, 
and $22-\mathrm{kD}$ IMP of rat liver peroxisomes and goat antirabbit IgG, horseradish peroxidase conjugate (Bio-Rad, Watford, England). Purification of rat peroxisomal membrane polypeptides and preparation of antibodies were performed according to Hashimoto et al. (23). Cross-reactivity of these antibodies against rat enzymes to human subjects was confirmed in previous report (19).

Pulse-chase experiments of fibroblasts. Skin fibroblasts from two controls and two patients with Zellweger syndrome were cultivated in Eagle's MEM (Nissui, Tokyo, Japan) supplemented with $10 \%$ FCS (GIBCO, Grand Island, NY) in $20 \mathrm{~cm}^{2}$ dishes. At the time of confluency, the cells in each dish were preincubated with $5 \mathrm{ml}$ of MEM free of methionine for $1 \mathrm{~h}$, then the medium was replaced with fresh methionine-free medium $(1 \mathrm{~mL})$ supplemented with $0.5 \mathrm{mCi}$ of $\left[{ }^{35} \mathrm{~S}\right]$ methionine $(>1000 \mathrm{Ci} / \mathrm{mmol}$, Amersham, Buckinghamshire, England). The cells were cultivated for $2 \mathrm{~h}$ in the labeled medium (pulse labeling) then were harvested immediately after labeling, or chased for 6 or $24 \mathrm{~h}$ with fresh MEM supplemented with methionine. The harvested cells were suspended in $0.5 \mathrm{~mL}$ of immunoprecipitation buffer $(10 \mathrm{mM}$ Tris- $\mathrm{HCl}, \mathrm{pH} 7.4 / 2 \mathrm{mM}$ EDTA/0.1\% SDS/0.1\% Triton $\times-100 / 10 \mathrm{mM}$ methionine $/ 0.1 \% \mathrm{BSA} / 10 \mu \mathrm{g} / \mathrm{mL}$ of protease inhibitors), frozen and thawed three times, sonicated for $30 \mathrm{~s}$, and centrifuged. Supernatants were immunoprecipitated with anti-70-, 26-, and 22-kD IMP and then subjected to SDS/PAGE and fluorography as described (24).

Subcellular distribution of the radiolabeled IMP in the fibroblasts was investigated as follows. Fibroblasts pulse labeled or chased as mentioned above were suspended in $0.5 \mathrm{~mL}$ of buffer consisting $10 \mathrm{mM}$ Tris- $\mathrm{HCl}, \mathrm{pH} 7.4 / 2 \mathrm{mM}$ EDTA/10 mM methionine $/ 0.1 \% \mathrm{BSA}$, frozen and thawed, sonicated, and centrifuged for $45 \mathrm{~min}$ at $40000 \mathrm{rpm}$. The supernatant was immediately immunoprecipitated. The pellet was resuspended with $0.5 \mathrm{~mL}$ of immunoprecipitation buffer, sonicated, immunoprecipitated and subjected SDS/PAGE, as described above.

\section{RESULTS}

Immunoblot analysis. Immunoblot analysis of peroxisomal IMP, using the membrane fractions of liver tissues revealed that the $70-\mathrm{kD}$ IMP was scanty in all three patients with Zellweger syndrome (Fig. 1A, lanes 4, 5, and 6), whereas this IMP was clearly detected in the controls (lanes 2,3 , and 7) and from a rat (lane 8). The 22-kD IMP was detected in two of the three patients (Fig. $1 B$, lanes 4 and 5 ) and in all of the controls (lanes 4,5 , and 6 ). However, the amount of the 22-kD IMP in these patients was far less than that in the controls and it was not detected in one patient (lane 6). This polypeptide was soon undetectable when the sample of the patient was stored at $-20^{\circ} \mathrm{C}$ for a long time or in case of several freezings and thawings (data not shown). The 26-kD IMP was hardly detectable in human tissues by the method we used.

Pulse-chase experiments of fibroblasts. Pulse labeling with $\left[{ }^{35} \mathrm{~S}\right]$ methionine revealed that the $70-\mathrm{kD}$ IMP was synthesized in fibroblasts from the patients, at a level similar to that seen in the controls (Fig. 2A, P). The size of the pulse-labeled precursor polypeptide was identical to that of mature polypeptide in the chase experiment, as in the case of experiments on rats (15). These bands remained clear by the 6-h chase experiment (Fig. $2 A, 6)$ and became fainter by the 24 -h chase (Fig. $2 A, 24$ ). There was no significant difference in the degradation rates between tissues from the patients and from the controls.

The radiolabeled 26-kD IMP was detected in tissues from both patients and controls, at a similar level, in the pulse and the chase experiments (Fig. 2B). A slightly larger band (about 27 $\mathrm{kD}$ ) was detected in every lane. Because the anti-26-kDa antibody used is known to cross-react with the 27-kD IMP (23), this larger band may be the $27-\mathrm{kD}$ IMP. The relationship between these two polypeptides remains to be elucidated.

The 22-kD IMP was also synthesized in all cell lines tested (Fig. 2C). Degradation rate of this polypeptide in tissues from

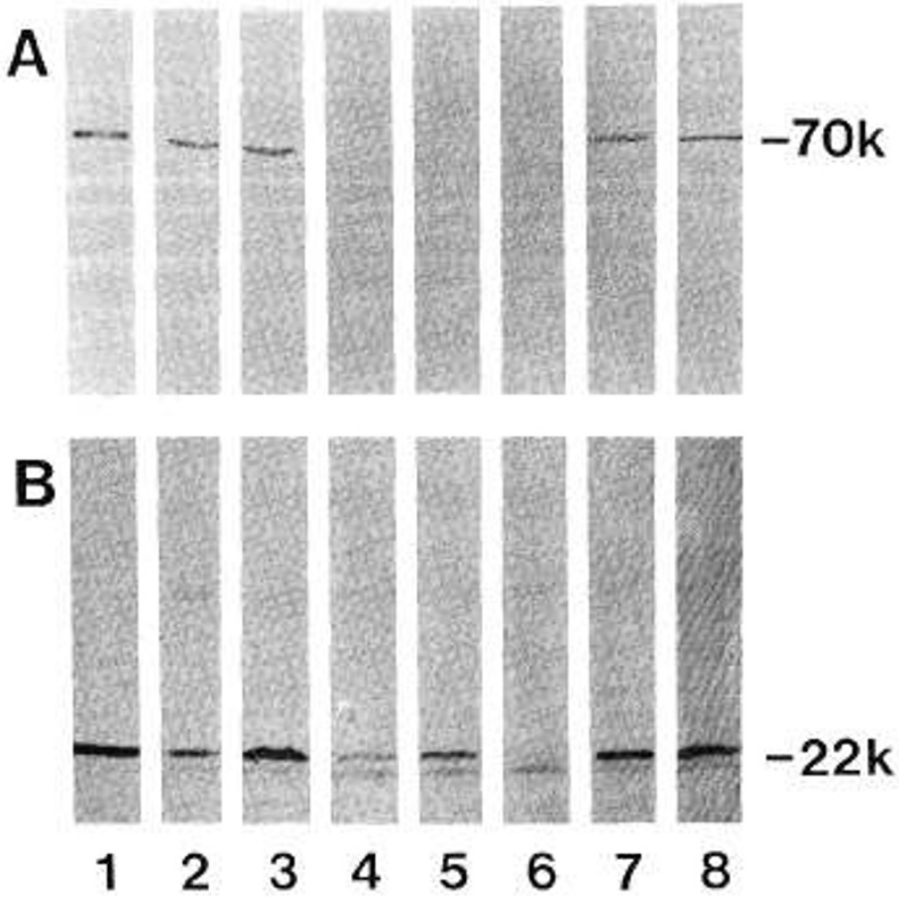

Fig. 1. Immunoblot analysis of peroxisomal membrane polypeptides. Membrane fractions of autopsied liver tissue from patients with Zellweger syndrome and controls were subjected to SDS/PAGE and Western blotting. Membrane polypeptides were located as described in Methods. A 70-kD IMP $(A)$ was not detected in the patients with Zellweger syndrome (lanes 4,5 , and 6 ), whereas it was clearly seen in the control (lanes 3, 7, and 8 ) and rat (lane 2) livers. A 22-kD IMP $(B)$ was detected in two of the three patients in a small quantity. Lane 1 , purified rat membrane polypeptide.

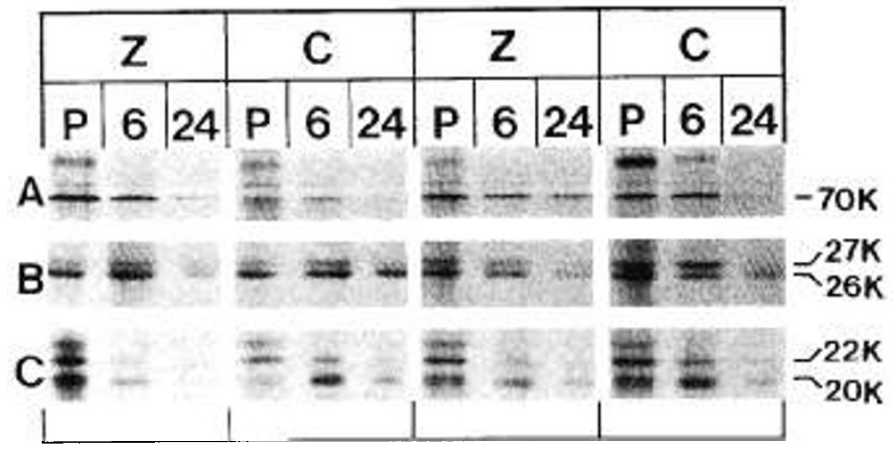

Fig. 2. Pulse-chase experiments of fibroblasts. Cultured skin fibroblasts from the patients with Zellweger syndrome and the controls were pulse-labeled with $\left.{ }^{35} S\right]$ methionine and chased for 6 or $24 \mathrm{~h}$ as described in "Materials and Methods." A 70-kD IMP $(A), 26-\mathrm{kD} \operatorname{IMP}(B)$, and 22kD IMP $(C)$ were synthesized in the pulse-label $(P)$ in both the patients with Zellweger syndrome $(Z)$ and the control $(C)$. No significant difference in the degradation was noted in the 6-h chase (6) and 24-h chase (24).

the patients was also similar to that in the controls. The smaller band (about $20 \mathrm{kD}$ ) found in tissues from both patients and controls was probably formed by the proteolytic degradation of 22-kD IMP, as described by Fujiki et al. (13)

Subcellular localization of IMP synthesized in pulse-chase experiments was also investigated (Fig. 3). Catalase, one of the matrix enzymes of peroxisomes, was detected in the soluble fraction, but not in the membrane fraction in the control after the cells were sonicated and ultracentrifuged (Fig. $3 A$ ). This was likely due to the destruction of the structure of peroxisomes by 


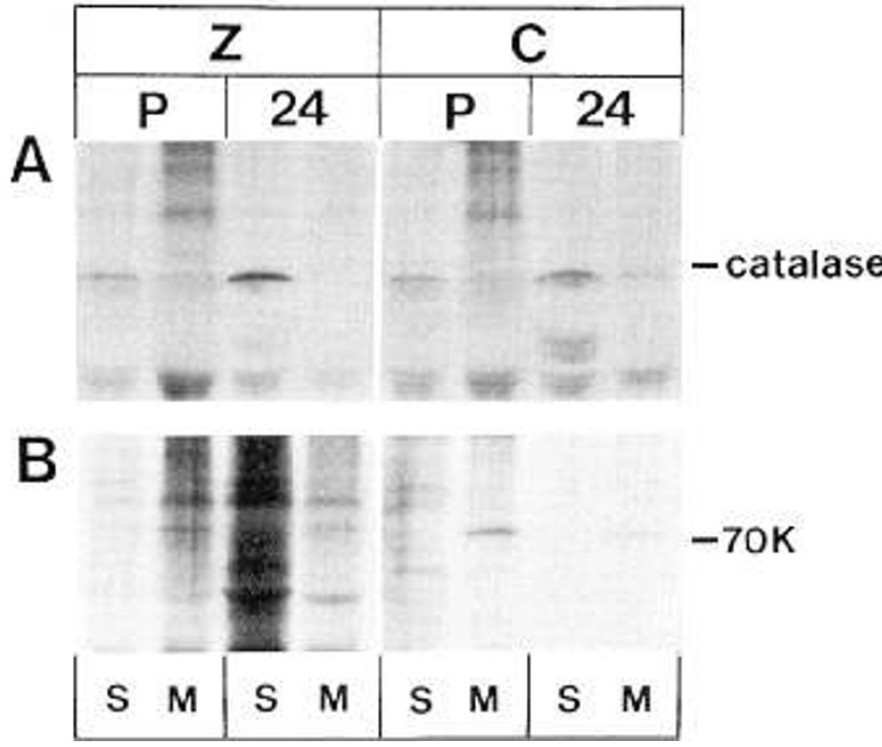

Fig. 3. Subcellular distribution of radiolabeled 70-kDa IMP. Fibroblasts were pulse-labeled with $\left[{ }^{35}\right.$ S]methionine, then soluble and membrane fractions were prepared, as described in "Materials and Methods." Catalase $(A)$ was detected in the soluble fraction $(S)$, whereas 70-kD IMP $(B)$ was predominantly detected in the membrane fraction $(M)$ in both the patients with Zellweger syndrome $(Z)$ and the controls $(C)$. Heavy background in $\mathrm{B}$ was due to insufficient washing after immunoprecipitation. $P$, pulse labeling for $2 \mathrm{~h} ; 24$, chase for $24 \mathrm{~h}$.

the sonication. In the patient with Zellweger syndrome, in whom catalase was shown to be present in the cytosol (25), this enzyme was also detected in the soluble fraction. However, the $70-\mathrm{kD}$ IMP was detected in the membrane fraction and not in the soluble fraction, in tissues from both patients and controls (Fig. $3 B$ ). These results suggest that IMP synthesized in fibroblasts are localized in the disorganized peroxisomal membrane in patients with Zellweger syndrome.

\section{DISCUSSION}

Biochemical analyses revealed a number of polypeptides on the membrane of peroxisomes. IMP with $M_{\mathrm{r}}$ of 22-,67.7-, and 69.7-kD were purified by Fujiki et al. (26). Hashimoto et al. (23) purified 70-, 68-, 41-, 27-, 26-, and 22-kDa IMP and demonstrated their induction with the administration of di(2-ethylhexyl)phthalate, a peroxisomal proliferating agent, in parallel with the enzymes of peroxisomal $\beta$-oxidation (23). IMPs of peroxisomes are synthesized on free polysomes, as in the case of matrix enzymes of peroxisomes (15).

These investigations support the hypothesis that peroxisomes are formed by fission from preexisting peroxisomes and suggest that membrane polypeptides play important roles in the biogenesis of peroxisomes, integrity of peroxisomal membrane, transport of metabolites, and localization of peroxisomal matrix enzymes. This suggests the possibility that a defect in a peroxisomal membrane polypeptide might be responsible for the primary etiology of the peroxisome-deficient disorders including Zellweger syndrome, neonatal adrenoleukodystrophy and infantile Refsum's disease. Lazarow et al. (19) reported that the 22-kD polypeptide was present in the membrane fraction of liver tissues from patients with Zellweger syndrome. They speculated that the peroxisomal membranes are assembled in patients with this syndrome, but may be defective for the import of matrix proteins (17). Small et al. (27) reported the presence of $70-\mathrm{kD}$ (referred to as $69 \mathrm{kD}$ ), $53-\mathrm{kD}$ and $22-\mathrm{kD}$ IMP in livers from patients with Zellweger syndrome, infantile Refsum's disease, and X-linked adrenoleukodystrophy (27).

In our study, we found that the $70-\mathrm{kD}$ polypeptide was defi- cient in all of three Japanese patients with Zellweger syndrome, and the $22-\mathrm{kD}$ polypeptide was presented in two of three patients, albeit the amount being scanty. The difference between Japanese and American (and Australian) patients may be due to different genetic defects as demonstrated by Brul et al. (28), or simply due to postmortem change. Pulse-chase experiments of fibroblasts from our patients revealed that at least 70-, 26-, and $22-\mathrm{kD}$ polypeptides were synthesized at levels similar to those in the controls. The $70-\mathrm{kD}$ polypeptide was integrated into the membrane fraction of cells soon after being synthesized on free polysomes in the cytosol; yet the precise location within the membrane was not elucidated. These observations suggest that $70-\mathrm{kD}$ IMP probably localizes in a rudimentary membrane of the peroxisomes in patients with Zellweger syndrome. The other two polypeptides are also probably integrated into the peroxisomal membrane although this was not confirmed because of the low sensitivity of our assay. The results also indicate that deficiency of the 70-26-, or 22-kD IMP is not the primary defect in Zellweger syndrome. However, the functions of these IMP, which remain to be elucidated, may be defective in this syndrome. The absence of IMP on immunoblot analysis may related to the slightly more rapid degradation not detectable by the 24-h chase, to a different state of defective peroxisomes between hepatocytes in vivo and fibroblasts, or to autolysis. Functional and molecular analysis of peroxisomal IMP may be important for the elucidation of primary etiology of Zellweger syndrome and the other generalized peroxisomal disorders.

Acknowledgments. The authors are grateful to Professor K. Tada (Department of Pediatrics, Tohoku University School of Medicine, Sendai) for the liver sample from a patient with Zellweger syndrome and to $\mathrm{M}$. Ohara for comments.

\section{REFERENCES}

1. Bowen P, Lee C, Zellweger H, Lindenberg R 1964 A familial syndrome of multiple congenital defects. Bull Johns Hopkins Hosp 114:402-414

2. Goldfischer S, Moore CL, Johnson AB, Spiro AJ, Valsamis MP, Wisniewski HK, Ritch RH, Norton WT, Rapin I, Gartner LM 1973 Peroxisomal and mitochondrial defects in the cerebro-hepato-renal syndrome. Science 182:62-64

3. Schutgens RBH, Heymans HSA, Wanders RJA, van den Bosch H, Tager JM 1985 Peroxisomal disorders: a newly recognized group of genetic diseases. Eur J Pediatr 144:430-440

4. Suzuki Y, Shimozawa N, Orii T, Igarashi N, Kono N, Matsui A, Inoue $Y$, Yokota S, Hashimoto T 1988 Zellweger-like syndrome with detectable hepatic peroxisomes: a variant form of peroxisomal disorder. J Pediatr 113:841-845

5. Tager JM, ten Harmsen van der Beek WA, Wanders RJA, Hashimoto T, Heymans HSA, van den Bosch H, Schutgens RBH, Schram AW 1985 Peroxisomal $\beta$-oxidation enzyme proteins in the Zellweger syndrome. Biochem Biophys Res Commun 126:1269-1275

6. Suzuki Y, Orii T, Mori M, Tatibana M, Hashimoto T 1986 Deficient activities and proteins of peroxisomal $\beta$-oxidation enzymes in infants with Zellweger syndrome. Clin Chim Acta 156:191-196

7. Heymans HSA, Schutgens RBH, Tan R, van den Bosch H, Borst P 1983 Severe plasmalogen deficiency in tissues of infants without peroxisomes (Zellweger syndrome). Nature 306:69-70

8. Datta NS, Wilson GN, Hajra A 1984 Deficiency of enzymes catalyzing the biosynthesis of glycerol-ether lipids in Zellweger syndrome. $N$ Engl $J \mathrm{Med}$ 311:1080-1083

9. Poulos A, Sharp F, Whiting M 1984 Infantile Refsum's disease (phytanic acid storage disease) A variant of Zellweger syndrome? Clin Genet 26.579-586

10. Wanders RJA, Romeyn GJ, van Roermund CWT, Schutgens RBH, van den Bosch H, Tager JM 1988 Identification of 1-pipecolate oxidase in human liver and its deficiency in the Zellweger syndrome. Biochem Biophys Res Commun 154:33-38

11. Novikoff AB, Novikoff PM 1982 Microperoxisomes and peroxisomes in relation to lipid metabolism. Ann NY Acad Sci 386:138-152

12. Lazarow PB 1980 Properties of the natural precursor of catalase: implications for peroxisome biogenesis. Ann NY Acad Sci 343:293-303

13. Furuta S, Hashimoto T, Miura S, Mori M, Tatibana M 1982 Cell-free synthesis of the enzymes of peroxisomal $\beta$-oxidation. Biochem Biophys Res Commun 105:639-646

14. Fujiki Y, Rachubinski RA, Lazarow PB 1984 Synthesis of a major integral membrane polypeptide of rat liver peroxisomes on free polysomes. Proc Natl Acad Sci USA 81:7127-7132

15. Suzuki Y, Orii T, Takiguti M, Mori M, Hijikata M, Hashimoto T 1987 Biosynthesis of membrane polypeptides of rat liver peroxisomes. J Biochem 
$101: 491-496$

16. Goldfischer S, Collins J, Rapin I, Coltoff-Schiller B, Chang CH, Nigro M, Black VH, Javitt NB, Moser HW, Lazarow PB 1985 Peroxisomal defects in neonatal onset and X-linked adrenoleukodystrophy. Science 227:67-70

17. Lazarow PB, Fujiki Y, Small GM, Watkins P, Moser HW 1986 Presence of the peroxisomal $22-\mathrm{kDa}$ integral membrane protein in the liver of a person lacking recognizable peroxisomes (Zellweger syndrome). Proc Natl Acad Sci USA 83:9193-9196

18. Santos MJ, Imanaka T, Shio H, Small GM, Lazarow PB 1988 Peroxisomal membrane ghosts in Zellweger syndrome-aberrant organelle assembly. Science 239:1536-1538

19. Suzuki X, Shimozawa N, Orii T, Aikawa J, Tada K, Kuwabara T, Hashimoto T 1987 Biosynthesis of peroxisomal membrane polypeptides in infants with Zellweger syndrome. J Inherited Metab Dis 10:297-300

20. Fujiki Y, Hubbard AL, Lowler S, Lazarow PB 1982 Isolation of intracellular membranes by means of sodium carbonate treatment: application to endoplasmic reticulum. J Cell Biol 93:97-102

21. Laemmli UK 1970 Cleavage of structural proteins during the assembly of the head of bacteriophage T4. Nature 227:680-685

22. Towbin H, Staehelin T, Gordon J 1979 Electrophoretic transfer of proteins from polyacrylamide gels to nitrocellulose sheets: procedure and some applications. Proc Natl Acad Sci USA 76:4350-4354
23. Hashimoto T, Kuwabara T, Usuda N, Nagata T 1986 Purification of membrane polypeptides of rat liver peroxisomes. J Biochem 100:301-310

24. Mori M, Miura S, Tatibana M, Cohen PP 1981 Cell-free translation of carbamyl phosphate synthetase I and ornithine transcarbamylase messenger RNAs of rat liver. J Biol Chem 256:4127-4132

25. Wanders RJA, Kos M, Roest B, Meyer AJ, Schrakamp G, Heymans HSA Tegelaers WHH, van den Bosch H, Schutgens RBH, Tager JM 1984 Activity of peroxisomal enzymes and intracellular distribution of catalase in Zellweger syndrome. Biochem Biophys Res Common 123:1054-1061

26. Fujiki Y, Fowler S, Shio H, Hubbard AL, Lazarow PB 1982 Polypeptide and phospholipid composition of the membrane of rat liver peroxisomes: comparison with endoplasmic reticulum and mitochondrial membranes. $J \mathrm{Cell}$ Biol 93:103-110

27. Small GM, Santos MJ, Imanaka T, Poulos A, Danks DM, Moser HW, Lazarow PB 1988 Peroxisomal integral membrane proteins in livers of patients with Zellweger syndrome, infantile Refsum's disease and X-linked adrenoleukodystrophy. J Inherited Metab Dis 11:358-371

28. Brul S, Westerveld A, Strijland A, Wanders RJA, Schram AW, Heymans HSA Schutgens RBH, van den Bosch H, Tager JM 1988 Genetic heterogeneity in the cerebrohepatorenal (Zellweger) syndrome and other inherited disorders with a generalized impairment of peroxisomal functions. J Clin Invest $81: 1710-1715$ 